\title{
DLX5 Regulates Development of Peripheral and Central Components of the Olfactory System
}

\author{
Jason E. Long, ${ }^{1 \star}$ Sonia Garel, ${ }^{1 \star}$ Michael J. Depew, ${ }^{1 \star}$ Stuart Tobet, ${ }^{2}$ and John L. R. Rubenstein ${ }^{1}$ \\ ${ }^{1}$ Nina Ireland Laboratory of Developmental Neurobiology, Department of Psychiatry, Programs in Biomedical Sciences, Developmental Biology, \\ Neuroscience and Oral Biology, Langley Porter Psychiatric Institute, University of California, San Francisco, San Francisco, California 94143-0984, and \\ ${ }^{2}$ The Shriver Center, Department of Biomedical Sciences and Physiology, University of Massachusetts Medical School, Waltham, Massachusetts 02452
}

Induction, neurogenesis, and synaptogenesis of the olfactory bulb are thought to require interactions with the olfactory epithelium. The Dlx family of homeobox genes is expressed in both the olfactory bulb and olfactory epithelium. In particular, Dlx 5 is expressed in the olfactory placode, olfactory epithelium, and local circuit neurons of the olfactory bulb. Here we analyzed mice lacking DLX5 function. The $D l x 5^{-/-}$mutation reduces the size of the olfactory epithelium. Although some olfactory neurons are formed, they fail to generate olfactory axons that innervate the olfactory bulb. Despite the lack of innervation, the olfactory bulb forms, and neurogenesis of projection and local circuit neurons proceeds. However, the mutation has a cell-autonomous effect on the ability of neural progenitors to produce olfactory bulb local circuit neurons, with granule cells more severely affected than periglomerular cells. In addition, the mutation has a noncell-autonomous effect on the morphogenesis of mitral cells.

Key words: Dlx5; local circuit neuron; olfactory bulb; olfactory epithelium; tangential migration; GABA

\section{Introduction}

The olfactory bulb $(\mathrm{OB})$ is an evagination from the rostral telencephalon that receives primary olfactory axonal innervation from neurons in the olfactory epithelium (OE). The OB is a laminar structure (see Fig. 9A) (Shepherd, 1998). Its outer nerve layer (ONL) consists primarily of olfactory afferent axons and ensheathing glia. The axons from olfactory neurons expressing a specific olfactory receptor converge, and synapse on, the dendrites of glutamatergic projection neurons (mitral and tufted cells) in structures called glomeruli. Interspersed between glomeruli are local circuit neurons (periglomerular cells), which send their dendrites into the glomeruli of the glomerular layer (PG). These neurons are both GABAergic and dopaminergic $\left[\sim 85 \%\right.$ of tyrosine hydroxylase ${ }^{+}(\mathrm{TH})$ cells are also $\mathrm{GABA}^{+}$in the PG] (Gall et al., 1987; Kosaka et al., 1995). Deep to the PG is the external plexiform layer (EPL), which contains the horizontal processes of tufted and mitral cells, the cell bodies of tufted cells, and the dendrites of a second type of GABAergic local circuit neuron (granule cells). The next layer, the mitral cell layer (MC), contains the cell bodies of the mitral cells. These neurons grow their axons into the fibrous internal plexiform layer (IPL). Below this fiber zone are the cell bodies of the granule cells, forming the granule cell layer (GC). Deep to the GC is the subventricular zone (SVZ), a reservoir of progenitor cells that produces new granule

Received July 16, 2002; revised 0ct. 31, 2002; accepted 0ct. 31, 2002.

This work was supported by the following: a grant from Nina Ireland and National Institute of Mental Health Grants R01 MH49428-01, R01 MH51561-01A1, and K02 MH01046-01 (J.L.R.R.); a grant from the Human Frontier Science Program (S.G.); and a grant from Achievement Rewards for College Scientists and National Institute of Dental Research Grant T32 DE07204 (M.J.D.). We thank members of the Rubenstein laboratory and Jaclyn Schwenker for helpful discussions and critical comments about this manuscript.

*J.E.L., S.G., and M.J.D. contributed equally to this work.

Correspondence should be addressed to John L. R. Rubenstein, Department of Psychiatry, University of California, San Francisco-Langley Porter Psychiatric Institute-Ireland Labs Room A102, 401 Parnassus Avenue, Box IRE 0984, San Francisco, CA 94143-0984. E-mail: jlrr@cgl.ucsf.edu.

Copyright $\odot 2003$ Society for Neuroscience $\quad 0270-6474 / 03 / 220568-\bullet \$ 15.00 / 0$ and periglomerular neurons in the adult brain (Hinds, 1968a,b; Altman, 1969; Luskin, 1993; Lois and Alvarez-Buylla, 1994; Goldman and Luskin, 1998). At the center of the OB are ependymal cells, the remnants of the neuroepithelial lining of the ventricle.

Development of the OB begins with its induction and evagination from the rostral telencephalon. There is evidence that signaling from the olfactory placode contributes to patterning the telencephalic anlage of the OB (Graziadei and Monti-Graziadei, 1992; De Carlos et al., 1995; LaMantia et al., 2000). Primary olfactory axons are also implicated in regulating the early neurogenesis within the OB (De Carlos et al., 1995; Gong and Shipley, 1995), although direct demonstration that olfactory afferents are essential for OB neurogenesis is lacking. The genesis and differentiation of $\mathrm{OB}$ projection and local circuit neurons are under distinct genetic controls. The projection neurons (mitral and tufted cells) have a pallial origin and are regulated by cortical transcription factors such as Tbr1 (Bulfone et al., 1998), whereas the local circuit neurons (periglomerular and granule cells) have a subpallial origin and are regulated by transcription factors such as Dlx1 and Dlx2 (Qiu et al., 1995; Bulfone et al., 1998).

The $D l x$ genes are homeodomain transcription factors that regulate development of multiple cell types derived from the subcortical telencephalon (Qiu et al., 1995; Anderson et al., 1997; Bulfone et al., 1998). Dlx1,Dlx2, Dlx5, and Dlx6 are expressed in precursors of telencephalic GABAergic and dopaminergic neurons. Their expression persists at lower levels in postmitotic neurons (Liu et al., 1997; Stuhmer et al., 2002a,b). In the telencephalon, expression of $D l x 5$ and $D l x 6$ generally occurs after $D l x 1$ and Dlx2 (Eisenstat et al., 1999; Stuhmer et al., 2002a,b).

Local circuit neuron development in the $\mathrm{OB}$ is sensitive to all $D l x$ mutations studied to date. Both $D l \times 1^{-/-}$and $D l \times 2^{-/-}$mutants have a reduction in $\mathrm{TH}^{+}$neurons (Qiu et al., 1995) (J. E. Long and J. L. R. Rubenstein, unpublished observations) and Dlx $1 \& 2^{-1-}$ mutants lack $>95 \%$ of $\mathrm{GABA}^{+}$and $\mathrm{TH}^{+}$neurons 


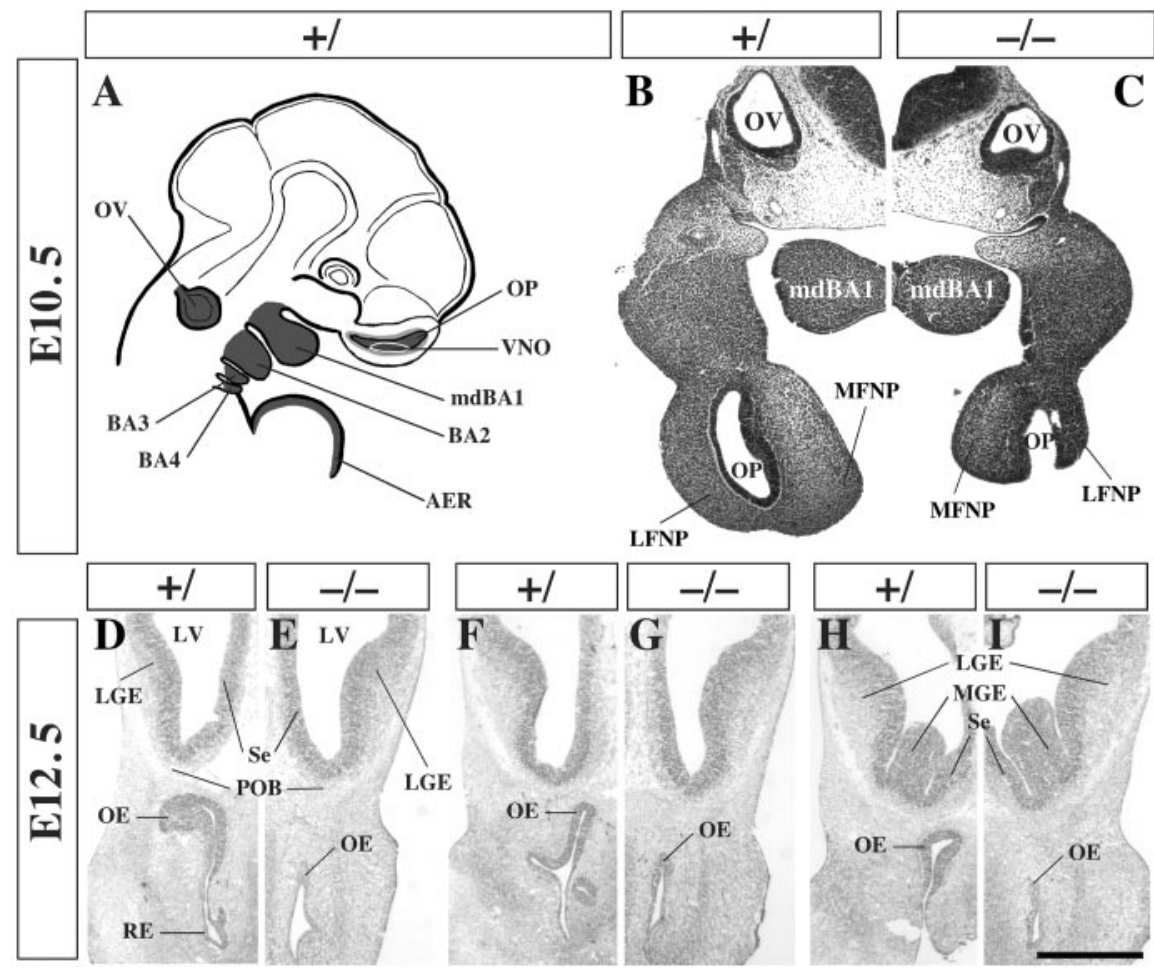

Figure 1. Analysis of 0 E development in E10.5 Gimori-stained $(B, C)$ and E12.5 Niss--stained $(D-I)$ control and D1 $\times 5^{-1-}$ mutant embryos. $A$, Schematic of D $1 \times 5$ expression in an E10.5 embryo (brain expression is not shown). $B, C$, The olfactory pit is smaller in the mutant $(C)$. In addition, the size of the lateral frontonasal process and medial frontonasal process are reduced. The hole in the mutant section $(C)$ is a sectioning artifact. $D-I$, Series of horizontal sections from rostral $(D, E)$ to caudal $(H, I)$ illustrating the reduction of $0 E$ size in the $D / x 5^{-/-}$mutant embryo $(E, G, I)$ compared with control $(D, F, H)$. Note the large distance between the mutant $0 \mathrm{E}$ and the telencephalon. $A E R$, Apical ectodermal ridge; $B A 2, B A 3, B A 4$, branchial archs $2,3,4 ; L F N P$, lateral frontonasal process; $L V$, lateral ventricle; $m d B A 1$, mandibular branchial arch $1 ; M F N P$, medial frontonasal process; $O P$, olfactory pit; $O V$, otic vesicle; $P O B$, primordial olfactory bulb; Se, septum; VNO, vomeronasal organ. Scale bar (in I): $B-I, 400 \mu \mathrm{m}$. gradient of sucrose to $30 \%$, frozen in embedding medium (OCT; Tissue-Tek, Miles, Torrance, $\mathrm{CA}$ ), and cut using a cryostat or dehydrated in ethanol, embedded in paraffin, and cut using a microtome.

In situ hybridization. In situ hybridization experiments were performed using ${ }^{35} \mathrm{~S}$ riboprobes on $10 \mu \mathrm{m}$ frozen sections as described previously (Bulfone et al., 1993). We generously thank the following people for cDNAs: Drs. Brian Condie (Medical College of Georgia, Augusta, GA) (GAD67), Peter Gruss (Max Planck Institute of Biophysical Chemistry, Gottingen, Germany) (Pax6), Tom Curran (St. Jude Children's Hospital, Memphis, TN) (Reelin), Dona Chikaraishi (University of Rochester, Rochester, NY) (TH), and Francois Guillemot (Centre National de la Recherche Scientifique/Institut National de la Santé et de la Recherche Médicale/Universite Louis Pasteur, Strasbourg, France) (Hes5). The Dlxl, $D l \times 2$, and $D l \times 5$ plasmids were generated in the Rubenstein laboratory.

Histochemistry. Samples were sectioned at 10 $\mu \mathrm{m}$ and mounted onto SuperFrost Plus slides (Fisher, Pittsburgh, PA). Sections were stained with either Gimori trichrome (E10.5) on paraffin-embedded sections or cresyl violet [E12.5 to postnatal day $0(\mathrm{P} 0)]$ on OCTembedded sections and analyzed.

Bromodeoxyuridine labeling. Pregnant female mice were injected intraperitoneally with $40 \mathrm{mg} / \mathrm{kg}$ bromodeoxyuridine (BrdU) (Sigma, St. Louis, MO) and killed either 60 min later (see Fig. 7) or at E18.5 (see Fig. 8) as described previously (Anderson et al., 1997)

Immunohistochemistry. Immunohistochemistry was performed as described previously (Marin et al., 2000). We used the following pri(Bulfone et al., 1998). Dlx1\& $2^{-/-}$mutants also lack Dlx5 expression in most regions of the forebrain (Anderson et al., 1997; Zerucha et al., 1997), and, therefore, it is possible that the local circuit neuron defects in these mutants arise from DLX5 deficiency. To address this possibility, we investigated OB development of $D l \times 5^{-\prime-}$ mutant animals.

Dlx5 is expressed in multiple components of the olfactory system. It is expressed in the olfactory placode and in the OE; its expression in the olfactory placode is required for morphogenesis of the skeleton of the frontonasal prominence (Acampora et al., 1999; Depew et al., 1999). Dlx5 is also expressed in the SVZ, GC, and $\mathrm{PG}$ of the OB. Here we focus on the role of DLX5 regulating the development of the $\mathrm{OE}$ and $\mathrm{OB}$.

\section{Materials and Methods}

Animals and tissue preparation. A mouse mutant strain with a null allele of Dlx 5 was used in this study (Depew et al., 1999). This mouse strain was maintained by backcrossing to C57BL/6J mice for more than 10 generations. For staging of embryos, midday of the vaginal plug was calculated as embryonic day 0.5 (E0.5). Mouse colonies were maintained in accordance with the protocols approved by the Committee on Animal Research at University of California, San Francisco. Animals expected to contain $D l x 5^{-1-}$ mutant embryos were killed by cesarean section. PCR was performed as described previously (Bulfone et al., 1993; Depew et al., 1999) to genotype offspring resulting from $D l x 5$ heterozygous matings. Heterozygous and wild-type embryos showed the same phenotype, so both are used as controls throughout this paper. Embryos were anesthetized by cooling, dissected, and immersion fixed in $4 \%$ paraformaldehyde (PFA) in PBS for 4-12 hr. Samples were either cryoprotected in a mary rabbit polyclonal antibodies: anti-NPY (diluted 1:3000; Incstar, Stillwater, MN); anti-GAD65 (diluted 1:1000; Chemicon, Temecula, CA); anti-GAD67 (diluted 1:2000; Chemicon); and anti-TBR1-c (diluted 1:100; kindly provided by Dr. M. Sheng, Howard Hughes Medical Institute, Massachusetts General Hospital, Harvard Medical School, Boston, MA). We used the following mouse monoclonal antibodies: anti- $\beta$-III tubulin (diluted 1:200; Promega, Madison, WI); anti-GAP43 (diluted 1:1000; Chemicon); and anti-REELIN (diluted 1:500; kindly provided by Dr. A. Goffinet, University of Louvain Medical School, Brussels, Belgium). We used the following rat monoclonal antibodies: anti-NCAM (diluted 1:100; Sigma); and anti-BrdU (diluted 1:10; Harlan, Crawley Down, Sussex, UK). We used the following goat polyclonal antibody: anti-OMP (olfactory marker protein) (diluted 1:2000; kindly provided by Dr. F. Margolis, University of Maryland School of Medicine, Baltimore, MD).

Cell counting. To estimate the total cell numbers in the olfactory bulb, $10 \mu \mathrm{m}$ coronal (transverse) cryostat sections were stained with $50 \mu \mathrm{g} / \mathrm{ml}$ Hoechst 33342 (Molecular Probes, Eugene, OR). Wild-type olfactory bulbs had $82 \pm 5$ sections ( $n=25$ embryos), whereas the Dl $x 5^{-/-}$mutant olfactory bulbs had only $48 \pm 4$ sections ( $n=25$ embryos). Then, the number of cells within a $560 \times 80 \mu \mathrm{m}$ area of the wild-type and $D l \times 5^{-1-}$ mutant olfactory bulbs was counted. This area extended from the olfactory ventricle to the surface of the olfactory bulb. The wild types $(n=4)$

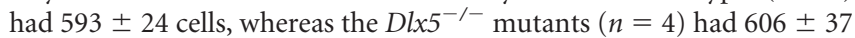
cells. Thus, the overall cell density within the wild-type and $D l \times 5^{-1-}$ mutant olfactory bulb was determined to be similar. However, because the length of the $D l x 5^{-1-}$ mutant olfactory bulb is $\sim 60 \%$ that of the wild type, we estimate that the total number of cells in the $D l \times 5^{-/-}$mutant olfactory bulb is $\sim 60 \%$ that of the wild type.

To estimate the relative numbers of $\mathrm{GAD}^{+} 7^{+}$and Reelin ${ }^{+}$cells in 
wild-type and Dlx $5^{-/-}$mutant embryos, silver grains were counted on sections from in situ hybridization using GAD67 and Reelin probes. For $G A D 67^{+}$cells, silver grains were counted in the granule cell and periglomerular layers. Generally, the amount of GAD67 label in the Dl $x 5^{-/-}$mutant olfactory bulb was asymmetric; lateral-superior parts had the least labeling, and medial-inferior parts had the most. In the granule cell layer, there were $1854 \pm 62$ grains in the wild-type sections $(n=4)$ and a range of $621 \pm 23$ (lateral bulb) to $1228 \pm 37$ (medial bulb) grains in $D l x 5^{-1-}$ mutant embryos ( $n=$ 4). Thus, there is a $33-67 \%$ reduction in the number of silver grains in the granule cell layer of the $D l \times 5^{-1-}$ mutant embryo. In the periglomerular layer, the wild-type embryo had $1310 \pm 23$ grains $(n=4)$, whereas the $D l \times 5^{-1-}$ mutant had a range of $248 \pm 41$ (lateral bulb) to $1095 \pm 11$ (medial bulb) grains $(n=4)$. Thus, there is a $16-82 \%$ reduction in the number of silver grains in the periglomerular layer of the $D l x 5^{-/-}$mutant embryo. In the mitral cell layer, there were $1265 \pm 24$ grains in the wild-type embryo $(n=4)$ and $1642 \pm 37$ grains in the $D l \times 5^{-/-}$mutant embryo $(n=4)$. This is an $\sim 30 \%$ increase in the number of silver grains in the mitral cell layer of the $D l \times 5^{-/-}$ mutant embryo. Because the olfactory bulb is smaller in the Dlx $5^{-/-}$mutant, the increased Reelin hybridization signal in a given coronal section may reflect increased mitral cell packing density and not an increase in total mitral cells.

To count the number of S-phase cells, $\mathrm{BrdU}^{+}$cells resulting from a $1 \mathrm{hr}$ pulse of BrdU at E18.5 were counted in the ventricular-subventricular zones of the olfactory bulb. There were $599 \pm 16 \mathrm{BrdU}^{+}$cells in the wild-type ( $n=3$ sections) and $1101 \pm 33 \mathrm{BrdU}^{+}$cells in the $D l x 5^{-/-}$mutant ( $n=3$ sections). Thus, there is an $\sim 46 \%$ increase in the number of BrdU-positive cells in the ventricular and subventricular zones in the $D l \times 5^{-/-}$mutant.

DiI labeling. P0 Dlx $5^{-/-}$mutants and their wild-type littermates were immersion fixed with 4\% PFA, and their brains were then removed and kept in fixative. Crystals of the axonal tracer DiI (Molecular Probes) were placed into the lateral olfactory tract (LOT) to retrogradely label mitral cells of the OB. Crystals of similar shape and size (100-200 $\mu \mathrm{m}$ in diameter) were used in homozygous mutant and wild-type littermate embryos. Brains were kept in 4\% PFA at room temperature for 2-3 weeks to allow the DiI to diffuse. Subsequently, brains were embedded in $5 \%$ low-melting-point agarose (FMC Bioproducts, Rockland, MA), and 100 $\mu \mathrm{m}$ coronal sections were cut with a vibrating microtome (VT1000S; Leica, Nussloch, Germany). Sections were counterstained with $50 \mu \mathrm{g} / \mathrm{ml}$ Hoechst 33342 (Molecular Probes) and mounted using Aquamount (Polysciences, Warrington, PA).

Slice culture. Embryos were removed by cesarean section from timed pregnant $D l \times 5$ heterozygous female mice mated with $D l x 5$ heterozygous male mice. Brains were dissected in ice-cold Krebs' buffer as described previously (Marin et al., 2000) and embedded in 5\% low-melting-point agarose (FMC Bioproducts), and $250 \mu \mathrm{m}$ sagittal sections were cut with a vibrating microtome (VT1000S; Leica). Slices were then placed onto transwell membranes ( $8 \mu \mathrm{m}$ pore size, $24 \mathrm{~mm}$ diameter membrane; Costar, Acton, MA) that were coated previously with $1 \mathrm{mg} / \mathrm{ml}$ Vitrogen (Cohesion, Palo Alto, CA) for $1 \mathrm{hr}$. The transwell membranes containing the slices were placed into Neurobasal media containing 2\% B-27 supplement (Invitrogen, Gaithersburg, MD), 0.5\% glucose, 2\% glutamine, and $2 \%$ penicillin-streptomycin. The slices were then injected with a LacZencoding defective retroviral vector using a micromanipulator and nitrogen injector (Marin et al., 2000). The slices were placed in a $37^{\circ} \mathrm{C}$ incubator with $5 \% \mathrm{CO}_{2}$ for $72 \mathrm{hr}$. The slices were then processed for $\beta$-galactosidase histochemistry as described previously (Marin et al., 2000).

\section{Results}

Dl $x 5^{-/-}$mutants have a hypoplastic olfactory epithelium that fails to form normal axonal connections with the olfactory bulb $D l \times 5$ is expressed throughout the olfactory placode and later, in the olfactory pit, in addition to expression in other regions of the embryo (Fig. $1 \mathrm{~A}$ ). Its expression in the olfactory placode is essential for development of the underlying frontonasal prominence (Acampora et al., 1999; Depew et al., 1999). Additional analysis of olfactory placode derivatives shows that the $D l \times 5^{-/-}$mutant olfactory pit is small and lacks thickening of the medial epithelium at E10.5 (Fig. $1 B, C$ ). At later stages, the $\mathrm{OE}$ and vomeronasal organ are greatly reduced in size (Figs. $1 D-I, 2 A-H, 3 A-D$; and data not shown). The small neuroepithelium exhibits some normal molecular characteristics of differentiation, including the presence of $\beta$-III tubulin and NCAM proteins at E12.5 (Fig. $2 A-$ $D$ ), expression of the mutant allele $D l x 5^{m}$ (a transcript continues to be produced), Lhx2, Otx1, Otx2, and Pax6 RNA at E13.5 (data not shown) and expression of OMP at E18.5 (Fig. 2E-H). Although some olfactory axons appear to grow from the neuroepithelium and fasciculate (Fig. $2 B, D, F, H$, arrowheads), these have not been detected contacting the OB in the Dlx $5^{-/-}$mutant. This is further demonstrated by the lack of GAP43 and OMP expres- 


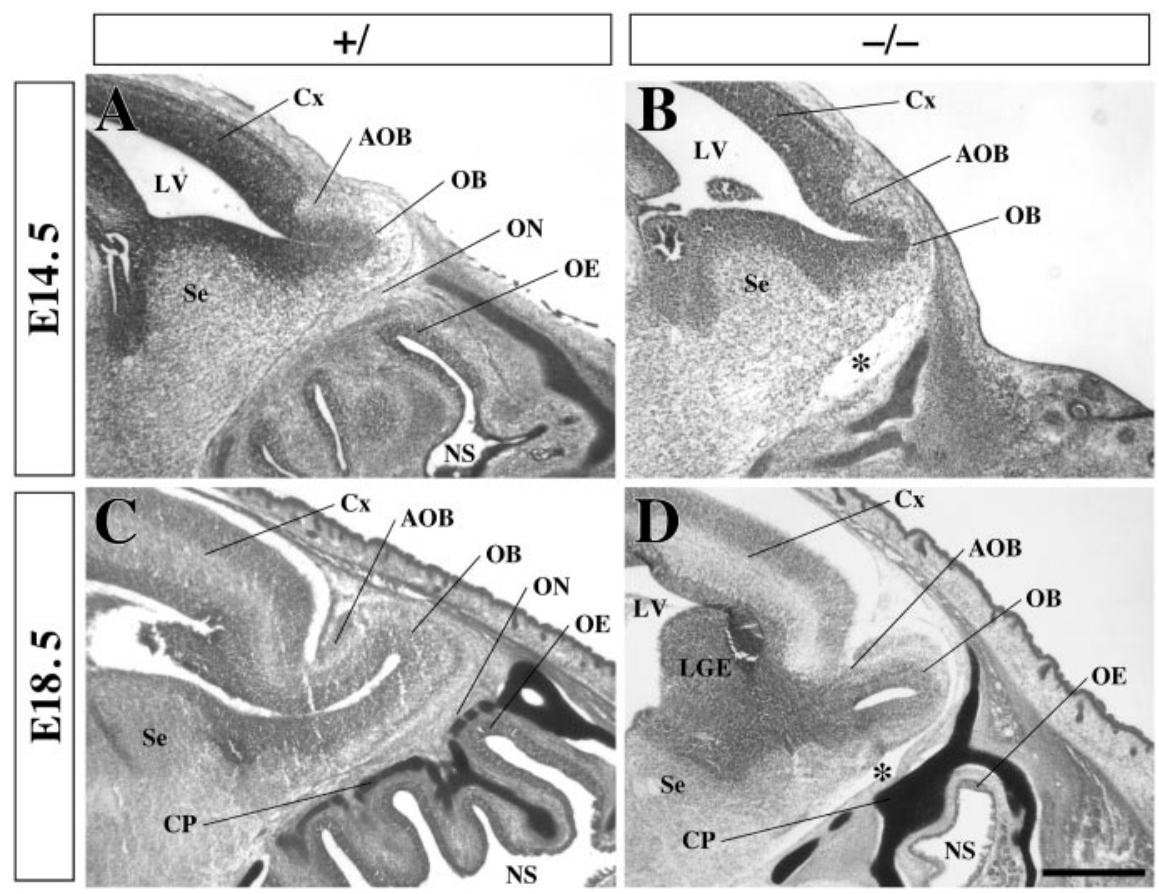

Figure 3. Nissl-stained sagittal sections of the telencephalon and $\mathrm{OE}$ from $\mathrm{E} 14.5(A, B)$ and $\mathrm{E} 18.5(C, D)$ control and $D / \times 5^{-1-}$ mutant embryos. At E14.5, it is already apparent that the $D / x 5^{-/-}$mutant $O B(B)$ is reduced in size when compared with controls $(A)$. In addition, there is also no $0 \mathrm{E}$ in this embryo, which occurs in $25 \%$ of the cases. At E18.5, the reduction in $0 \mathrm{~B}$ size is more apparent in $D / \times 5^{-1-}$ mutant embryos $(D)$. The mutant $O E$ is greatly reduced in size $(D)$. Additionally, there are few, if any, foramina in the cribiform plate of the mutant $(D)$. The asterisks in $B$ and $D$ indicate the space between the brain and cribiform plate that would normally be occupied by the olfactory nerve. $A O B$, Accessory olfactory bulb; $C P$, cribiform plate; $C x$, cortex; $L V$, lateral ventricle; $N S$, nasal sinus; $O N$, olfactory nerve; Se, septum. Scale bar (in $D$ ): $A-D, 310 \mu \mathrm{m}$.

sion on the surface of the main and accessory OBs at P0 (Fig. $2 I-L$ ), analysis of Nissl-stained sections at E14.5 and E18.5 (Fig. $3 A-D$ ), and DiI axon tracing from the $\mathrm{OE}$ at $\mathrm{P} 0$ (data not shown). The cribiform plate in the Dlx $5^{-/-}$mutant has a paucity of foramina for the passage of olfactory axons through the skull en route to the OB (Fig. $3 B, D$; and data not shown), further suggesting that few, if any, OE axons pass through the cribiform plate or even contact the OB. These results indicate that the Dlx $5^{-/-}$mutation results in a hypoplastic $\mathrm{OE}$ that fails to produce axons that contact the OB.

\section{Reduced GABAergic neuron production in the olfactory bulb of Dl $x 5^{-/-}$mutants}

Dlx5 expression is prominent in the subcortical telencephalon and its extension into the $\mathrm{OB}$ (Figs. $4 C, 5 A, C, E$ ). Although loss of DLX5 function does not appear to have a major effect on development of the basal ganglia (Figs. $3 A-D, 5 A-J$; and data not shown) (Acampora et al., 1999), the growth and histology of the $\mathrm{OB}$ are disrupted by this mutation, seen clearly at E14.5 and more dramatic at E18.5 (Figs. $3 A-D, 4 A-P, 5 A-R$ ). Nissl staining at E18.5 shows that $D l \times 5^{-/-}$mutants lack the distinct neuronal layers characteristic of the $\mathrm{OB}$ (Figs. $3 C, D, 4 I, J$ ) (see Fig. $7 E, F$ ). Coronal sections also suggest that the olfactory ventricle is smaller in the mutant (Figs. 2, 4, 6).

OB laminar organization was further studied at E18.5 using in situ hybridization on cross sections with RNA probes that define cell types in distinct layers (Fig. 4) (see Fig. 9A). For the progenitor layers, we examined the expression patterns of the $D l x$ gene family members. $D l x 1, D l x 2, D l \times 5$, and $D l x 6$ are differentially expressed in the progenitor and neuronal cell layers (Fig. 4A-D; and data not shown) (Dolle et al., 1992; Bulfone et al., 1998;
Stuhmer et al., 2002a). They are weakly expressed in the ventricular zone (VZ) and strongly expressed in the SVZ. The expression patterns of $D l \times 1, D l \times 2, D l \times 5^{m}$, and $D l x 6$ in the $D l \times 5^{-/-}$mutant suggest that the size of the SVZ, relative to the rest of the $\mathrm{OB}$, is increased.

To assess the development of OB local circuit neurons, we analyzed RNA expression of the Dlx genes GAD67, GABA transporter, $\mathrm{TH}$, and Pax6 and protein expression of GAD65 and TH (Fig. 4; and data not shown). Dlx1, Dlx2, Dlx5, and Dlx6 are expressed in the GABAergic and dopaminergic neurons of the GC and PG. The expression patterns of $D l \times 1, D l \times 2, D l \times 5^{m}$, and $D l x 6$ in the $D l \times 5^{-/-}$mutant show that the GC and PG are reduced (Fig. $4 A-D$; and data not shown) (see Fig. 9). Expression of GAD67, one of the enzymes that makes GABA, weakly marks the SVZ and strongly labels the GC and PG in the normal OB (Fig. 4E) (Behar et al., 1994). In the mutant, there is a prominent decrease in GAD67 expression, specifically, a decrease in the size and intensity of labeling in the GC and a slight reduction in the PG (Fig. 4E,F) (see Fig. 9). Expression of GAD65 protein is readily detectable in the GC and PG (Fig. 4G) (Feldblum et al., 1993; Esclapez et al., 1994). In the Dl $x 5^{-/-}$ mutant, there is a severe reduction of GAD65 granule cell expression, including their projections through the MC and EPL. In addition, the Dlx $5^{-/-}$mutant shows reduced GAD65 expression in the PG (Fig. 4G,H) (see Fig. 9). Expression of TH marks a subset of granule and periglomerular dopaminergic cells (Gall et al., 1987; Kosaka et al., 1995; Toida et al., 2000; Baker et al., 2001). In the Dl $x 5^{-/-}$mutant, expression of $\mathrm{TH}$ is almost eliminated from the GC and is reduced in the PG (Fig. $4 K, L$ ). Pax6 is coexpressed with $T H$ in periglomerular cells, is moderately expressed in the SVZ, and is strongly expressed in the VZ (Fig. 4M,N) (Gall et al., 1987; Stoykova and Gruss, 1994; Kosaka et al., 1995; Dellovade et al., 1998; Toida et al., 2000). Its expression in periglomerular cells is reduced similar to the reduction of $\mathrm{TH}$ (Fig. 4M,N) (see Fig. 9), consistent with their coexpression.

Estimates of olfactory bulb cell numbers were made on the basis of the $\sim 40 \%$ reduction of olfactory bulb length in the Dl $x 5^{-/-}$mutant and the numbers of Hoechst 33342-stained cells in wild-type and $D l \times 5^{-/-}$mutant olfactory bulb sections (data not shown; see Materials and Methods). The cell counts revealed an $\sim 40 \%$ reduction in the total number of OB cells. The change in cell number reflects the net result of decreases in granule and periglomerular cells and increases in VZ-SVZ cells (for counting data, see Materials and Methods). These results provide evidence that the $D l \times 5^{-/-}$mutation decreases the differentiation of progenitor cells, which leads to decreased numbers of $G A D 67^{+}$and $\mathrm{TH}^{+} \mathrm{OB}$ local circuit neurons.

Analysis of the projection neurons of the $\mathrm{OB}$ was performed using Reelin and Id2 expression. At E18.5, Reelin expression is primarily restricted to mitral cells (Bulfone et al., 1998). Although the MC lacks its prominence in Nissl- and Hoechststained sections of the $D l \times 5^{-/-}$mutants (Figs. $3 C, D, 4 I, J, 6 A, B$, 
$7 E, F)$, Reelin labeling of these cells is robust, and the pattern suggests that this layer is thicker than normal (Fig. 4O,P) (see Fig. 9). A similar result was observed with Id2 expression (data not shown) (Neuman et al., 1993). The thickened mitral cell layer in the Dlx $5^{-/-}$mutant may reflect increased cell density, which could be caused by packing a normal number of mitral cells into a smaller olfactory bulb.

\section{Subcortical migrations of local circuit} neurons are not appreciably affected in the Dlx $5^{-/-}$mutants

To evaluate potential mechanisms underlying the $D l \times 5^{-/-}$mutant OB phenotype, we studied the production of local circuit and projection neurons during development using in situ hybridization on parasagittal sections (Fig. 5). For local circuit neurons, we used $D l x 5$ expression to assess progenitors and GAD67 expression to assess postmitotic GABAergic cells. For projection neurons, we studied the expression of Reelin.

At E14.5, there appears to be at least three subcortical SVZ zones that are continuous with the SVZ of the OB; they are the SVZ of the septum, lateral ganglionic eminence (LGE), and medial ganglionic eminence (MGE). These zones are revealed by the expression of $D l x 5$ and GAD67 (Fig. 5A, C,G,I). The lateral side of the $\mathrm{OB}$ is continuous with $\mathrm{Dl} \times 5^{+}$and $G A D 67^{+}$cells in the LGE and the MGE (Fig. $5 A, G$ ). The medial side of the $\mathrm{OB}$ is continuous with $D l \times 5^{+}$and GAD67 ${ }^{+}$ cells in the septum (Fig. 5C,I). Dlx5- and GAD67-expressing cells enter the ventral side of the $O B$. These findings suggest that OB local circuit neurons are derived from several subcortical sources, which may generate cells that tangentially migrate into the $\mathrm{OB}$ via a ventral route.

The Dl $x 5^{-/-}$mutation did not grossly affect SVZ or mantle zone (laminas containing postmitotic neurons and their processes) expression of $D l x 5^{m}$ or GAD67 in the LGE, MGE, or septum (Fig. $5 B, D, H, J$ ). In addition, cortical $G A D 67^{+}$neurons, which are also primarily derived from $D l x$-expressing subcortical sources (Marin and Rubenstein, 2001), were not appreciably reduced (Fig. 5G-J). On the other hand, GAD67 expression in the mantle zone of the OB was reduced (Fig. $5 H, J$ ). This suggests that the early production of OB local circuit neurons is defective. Although early production of $\mathrm{OB}$ local circuit neurons is reduced, the generation of Reelin ${ }^{+}$projection neurons appears normal at E14.5 (Fig. 5M-P).

In situ hybridization analysis at E18.5 also showed that $D l \times 5^{m}$ and GAD67 expression in the OB SVZ appeared normal in $D l \times 5^{-1-}$ mutants, whereas the number of Dlx $5^{+}$and GAD67 OB neurons was reduced in the GC and PG (Fig. $5 E, F, K, L$ ). Reelin expression in the $\mathrm{MC}$ remained robust, but its tight laminar organization was disrupted (Fig. 5Q,R). Thus, the $D l \times 5^{-/-}$mutation causes the decreased production of $\mathrm{GAD} 7^{+}$local circuit neurons of
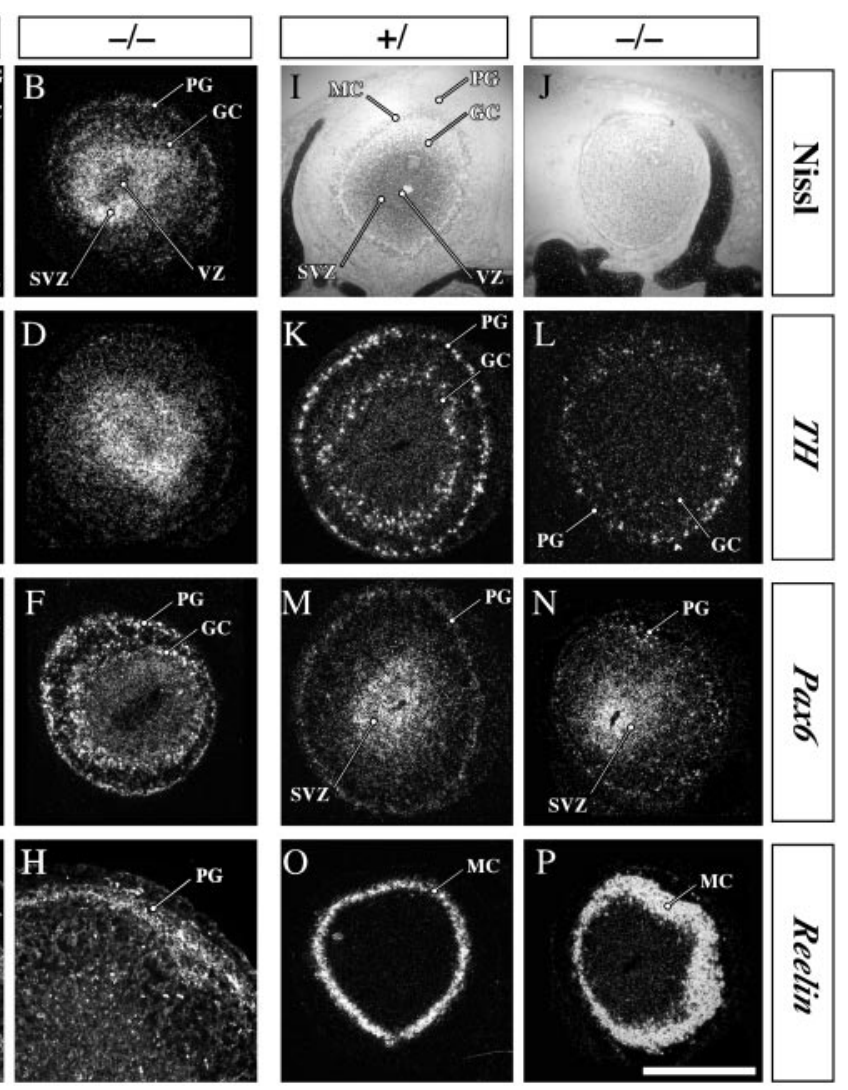

Figure 4. In situ RNA hybridization and immunofluorescence analysis of the expression of several local circuit neuron $(A-H$, . In situ analysis of $D / x 1$ and $D / \times 5$ in the wild-type embryo $(A, C)$ shows high expression in the $S V Z$, weaker expression in the VZ, organization similar to control embryos but at slightly reduced levels in the GC and PG. GAD67 expression in control embryos clearly 列 the $P G$ and $G C$ in controls $(G)$. The $D / \times 5^{-/-}$mutant has a severe reduction in granule cell somal and granule cell dendritic expression demonstrates a thickening of the $M C$ in $D / \times 5^{-/-}$mutant embryos $(P)$. Scale bar (in $P$ ): $A-F, I-P, 590 \mu \mathrm{m} ; G, H, 215 \mu \mathrm{m}$.

the OB from early ages and, although projection neuron production appears normal, the lamination of the MC is disrupted.

\section{Non-autonomous defect in mitral cell morphogenesis in the Dlx $5^{-/-}$mutants}

Although $D l \times 5$ is not expressed in mitral cells, and is probably not expressed in mitral cell precursors, we observed a noncellautonomous effect on the MC in the Dl $x 5^{-1-}$ mutant. As shown by Nissl and Hoechst staining (Figs. $4 I, J, 6 A, B, 7 E, F$ ) and by Reelin, Id2, and Tbr1 expression (Figs. 4O,P, 5Q,R, 6G-L; and data not shown), Dl $x 5^{-/-}$mutants have a thickened MC whose contour is irregular. To further evaluate this phenotype, we retrogradely labeled the mitral cells and their dendrites with DiI. DiI labeling in the LOT labeled the GC and IPL (consisting of mitral cell axons), mitral cells bodies in the MC, and their processes in the EPL and PG. In controls, mitral cells were regularly spaced and had radially oriented dendrites, whereas in the $D l \times 5^{-/-}$mutants, the orientation of the mitral cell dendrites was variable (Fig. $6 C-F)$. This result was confirmed by immunofluorescent double labeling of mitral cells for TBR1 (Fig. 6G, $H, K, L$, nuclear labeling) 


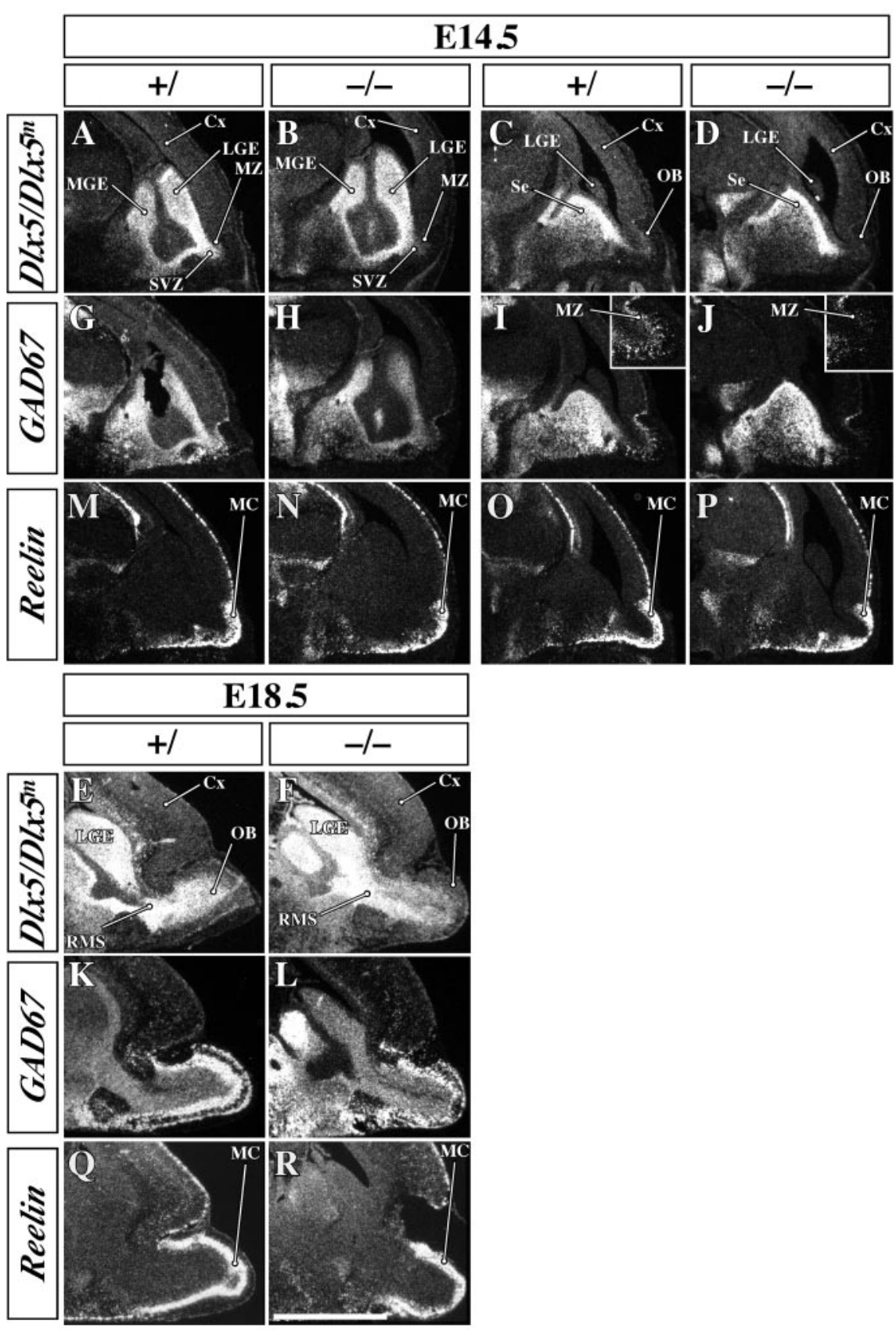

Figure 5. Expression of D/x5, GAD67, and Reelin at E14.5 and E18.5 in sagittal sections through the forebrain. In $A, B, G$, and $H$, expression in the LGE and MGE is continuous into the $O B$. In the $D / \times 5^{-/-}$mutant, there is a slight reduction in $D / \times 5^{m}$ and GAD67 expression in the $O B(A, B, G, H)$. DIx5 and $G A D 67$ expression is also continuous from the septum to the $O B(C, D, I, J)$. Insets in / and J show a higher magnification of the $O B$ at E14.5 revealing the reduction of GAD67 expression in the D/x $5^{-/-}$mutant embryo. Analysis of Reelin, a marker of the projection neurons of the $\mathrm{OB}$, shows virtually normal expression, despite the mutant $\mathrm{OBs}$ small size $(M-P)$. AtE18.5, the decreased expression of D/x $5^{m}$ and GAD67 further demonstrate the reduction of $G C$ and $P G$ in the $D / \times 5^{-1-}$ mutant $(E, F, K, L)$. However, at E18.5, Reelin expression is more diffuse in the $D 1 \times 5^{-/-}$mutant $(R)$ than in control ( $\left.Q\right)$. $C$, Cortex; $M Z$, mantle zone; Se, septum. Scale bar (in $R$ ): $A-R, 870 \mu \mathrm{m}$; insets in I, J, $1000 \mu \mathrm{m}$.

and REELIN (Fig. 6I-L, proximal dendrite labeling). This analysis provides additional evidence that the orientation of proximal dendrites was rotated, that the dendritic trees were smaller, and that the mitral cells and their axons were in the same layer (Fig. $6 G-L)$. These results further support the idea that the $D l \times 5^{-/-}$ mutation alters the morphology of the mitral cells. The potential mechanisms underlying this phenotype are considered in Discussion.
Analysis of proliferation and cell death in the olfactory bulbs of $\mathrm{Dl} \times 5^{-1-}$ mutants

The in situ hybridization analyses suggest that $D l \times 5^{-1-}$ mutants have a deficit in the production of local circuit neurons that begins as early as E14.5. To test whether this is attributable to a defect in the proliferation of $\mathrm{OB}$ progenitors, we used a BrdU incorporation assay at developmental stages when local circuit neurons constitute the majority of neurons being generated (Hinds, 1968a,b, 1972a,b). One hour after a pulse of BrdU at E14.5, E16.5, or E18.5, we identified the location of cells in S-phase of the cell cycle in coronal sections of Dl $\times 5^{-/-}$mutants and control littermates (Fig. $7 A-D, I, J$ ). At each of these ages, the BrdU pulse labeled three sets of cells: (1) OB progenitors in the VZ and SVZ; (2) cells in the ONL; and (3) mesenchymal cells surrounding the brain (i.e., meninges). In the Dl $\times 5^{-/-}$mutants, the size of the progenitor zone, and the density of S-phase cells within it, appeared approximately normal, although we cannot rule out a subtle change in the rate of proliferation in this layer.

In contrast, there was a reduction in the number of proliferating cells in the most superficial layer of the OB in the $D l \times 5^{-/-}$mutant at E16.5 and E18.5 (Fig. 7C,D,I,J). To confirm this finding, we used in situ hybridization with Hes5, a basic helix-loop-helix gene that is expressed in proliferating neural progenitors (Akazawa et al., 1992) and in cells of the ONL (Fig. 7G). In controls, Hes5 expression was high in the $\mathrm{VZ}$, moderate in the SVZ, and high in the ONL, whereas in the Dl $x 5^{-/-}$mutant, Hes5 expression appeared normal in the OB progenitor zones but was very low in the most superficial area of the OB (Fig. 7G,H). The proliferating cells in the ONL are known to differentiate into specialized glia, a subset of which express NPY (Ubink et al., 1994; Ubink and Hokfelt, 2000). These cells are derived from the olfactory placode-epithelium (Doucette, 1993; Mallamaci et al., 1996). Indeed, NPY expression in the ONL is greatly reduced at E18.5 in the Dlx $5^{-/-}$mutant (Fig. $7 \mathrm{~K}, L)$. The residual BrdU-labeled cells surrounding the mutant $\mathrm{OB}$ may correspond to mesenchymal cells, such as the meninges (Fig. $7 I, J$ ). Thus, the D $x 5^{-1-}$ mutation reduces the production of olfactory nerve glia, probably attributable to its function in the development of the OE.

To assess whether the decreased numbers of local circuit neurons could be attributable to increased levels of cell death, in either the progenitor or postmitotic cell populations, we used the terminal deoxynucleotidyl transferase-mediated biotinylated UTP nick end labeling (TUNEL) apoptosis assay. We found sim- 


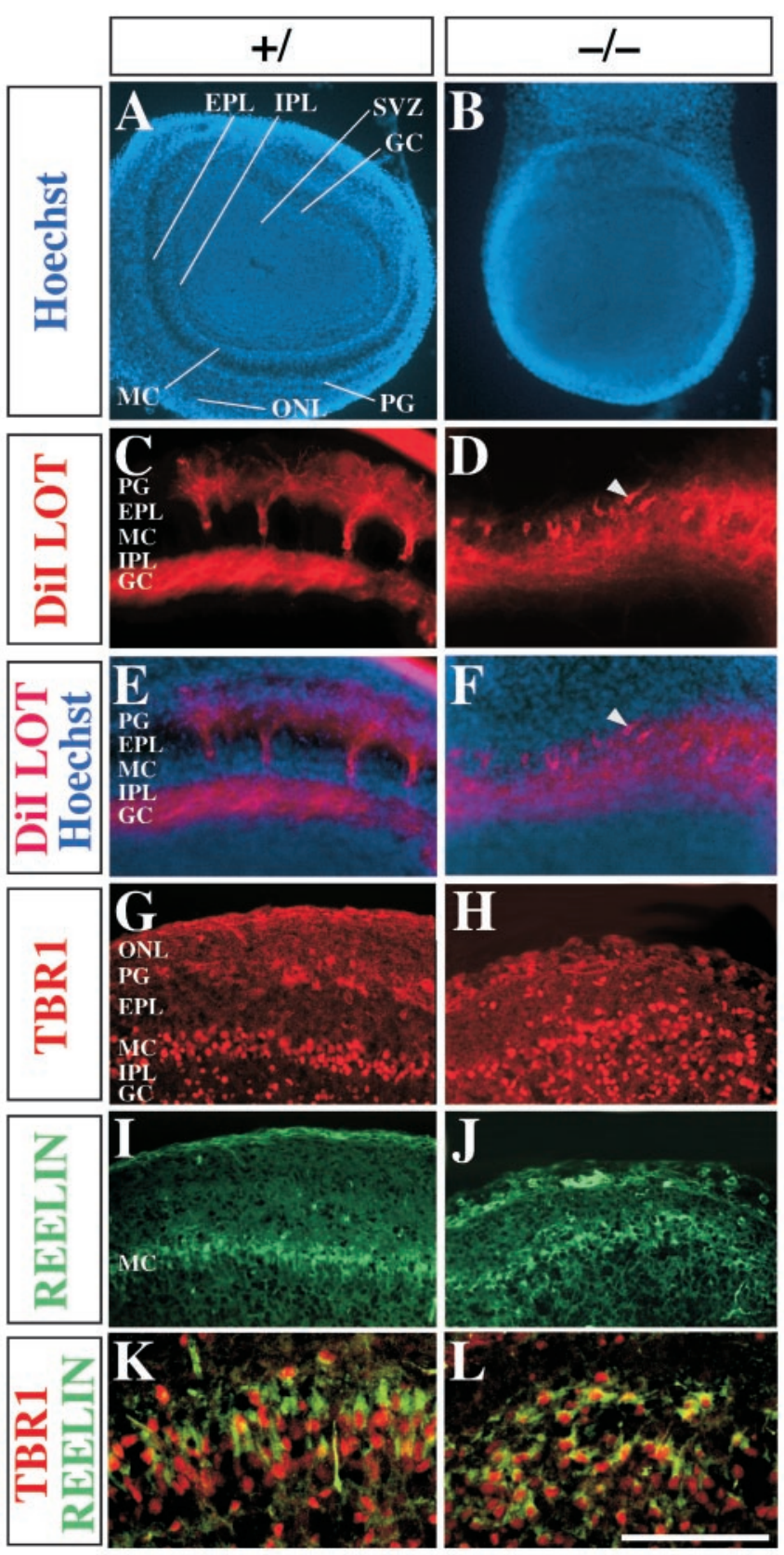

Figure 6. Cell non-autonomous defect in mitral cells revealed by Dil retrograde tracing and immunofluorescence. Hoechst staining of $\mathrm{P0}$ embryos reveals a defect in laminar organization in the $D\left(\times 5^{-1-}\right.$ mutants $(B)$. Dil placed into the LOT retrogradely labels mitral cells of the OB. In control embryos $(C, E)$, radially oriented mitral cell bodies and their radially extended dendritic processes are visible. In the $D 1 \times 5^{-/-}$mutants $(D, F)$, however, the orientation of the mitral cells is disorganized and their dendritic processes are small and disoriented (as shown by arrowheads). TBR1 (nuclear, $G$ ) and REELIN (proximal dendrite, I) immunofluorescence shows the MC in controls, which is disorganized in the mutant $(H, J)$. Colabeling of TBR1 (red) and REELIN ( green) in mitral cells is shown in $(K, L)$. Scale $\operatorname{bar}$ (in L): $A, B, 775 \mu \mathrm{m} ;(-J, 320 \mu \mathrm{m} ; K, L, 155 \mu \mathrm{m}$.

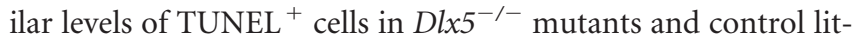
termates at E14 and E18 (data not shown). These results demonstrate that the $\mathrm{Dl} \times 5^{-/-}$mutation does not have a noticeable effect on cell death or proliferation using the methods that we used. However, there is a dramatic reduction in the number of BrdUlabeled cells in the most superficial layer of the $D l x 5^{-/-}$mutant $\mathrm{OB}$, which likely correspond to olfactory nerve glia.
Analysis of neuronal migration in the olfactory bulb and rostral migratory stream of $D l x 5^{-/-}$mutants

To assess whether the reduction in granule and periglomerular cells is attributable to defects in migration, we used BrdU birthdating and slice culture migration assays. BrdU pulses were performed on E14.5 and E16.5 embryos to label cells going through S-phase at that time. The BrdU-treated embryos were harvested on E18.5, and the positions of BrdU-labeled cells were analyzed in coronal sections of the OB. The majority of mitral cells are born before E14.5 (Hinds, 1968a,b, 1972a,b); therefore, labeled cells outside the progenitor zones in this experiment will tend to correspond to local circuit neurons, tufted cells, and glia (Hinds, 1968a,b, 1972a,b). BrdU exposure at E14.5 and E16.5 in control embryos led to BrdU incorporation into some cells that remained in the progenitor zones and some that were located superficially in the OB (Fig. $8 A-D$ ). In the Dlx $5^{-1-}$ mutants, fewer BrdUlabeled cells were present outside of the progenitor zone. This is particularly clear for the embryos labeled at E16.5 (Fig. 8C,D). Furthermore, labeling at E14.5 resulted in an accumulation of $\mathrm{BrdU}^{+}$cells in the SVZ (Fig. $8 A, B$, note the increased density of labeled cells in the SVZ and the very small olfactory ventricle), suggesting that the $D l x 5^{-/-}$mutation reduces the rate at which SVZ progenitors mature into neurons.

The BrdU results suggest that radial migration from the progenitor zone to the local circuit neuron layers is reduced in the Dlx $5^{-/-}$mutants, which could result from either reduced neuronal production or a defect in migration. To assess whether tangential migration along the rostral migratory stream (RMS) is affected by the $D l x 5^{-1-}$ mutation, we used a slice culture cell migration assay (Tobet et al., 1996) (Fig. 8E,F). Parasagittal vibrating microtome slices from E18.5 control and Dlx $5^{-/-} \mathrm{mu}-$ tant embryos were generated. We labeled the RMS with injections in five to six different locations using a $\mathrm{LaCZ}$-encoding replication incompetent retroviral vector. The slices were grown for $72 \mathrm{hr}$, and the locations of LacZ-expressing cells were assessed by $\beta$-galactosidase activity. The experiment showed that $D l x 5^{-1-}$ mutants have tangential migration in their RMS (Fig. $8 E, F)(n=$ 5 controls; $n=5 \mathrm{Dl} \times 5^{-/-}$mutants). Similar results were obtained using DiI labeling of migrating cells (data not shown). These results provide evidence that tangential migration still occurs in the $D l x 5^{-1-}$ mutants. Additional studies are needed to determine whether the efficiency of migration is reduced.

\section{Discussion}

Herein we show that DLX5 has a central role in the development of the primary structures involved in olfaction. Murine Dl $x 5^{-/-}$ mutants have a hypoplastic OE that fails to produce axons which innervate the OB. Despite the lack of innervation, the OB still forms, although with a reduced size and altered lamination. The size and lamination defects (Fig. 9) are contributed to by cellautonomous defects in local circuit neuron production and by a noncell-autonomous effect on the orientation and dendritic branching of the mitral cells.

Loss of normal olfactory input to the telencephalon is not essential for olfactory bulb neurogenesis

Previous studies have suggested that the olfactory placode and/or epithelium may have a key role in the initiation of $\mathrm{OB}$ development and neurogenesis (Graziadei and Monti-Graziadei, 1992; LaMantia et al., 1993, 2000; Gong and Shipley, 1995). Although $D l \times 5$ is expressed in the olfactory placode, $D l \times 5^{-1-}$ mutants are able to produce an olfactory pit and differentiate a small amount 


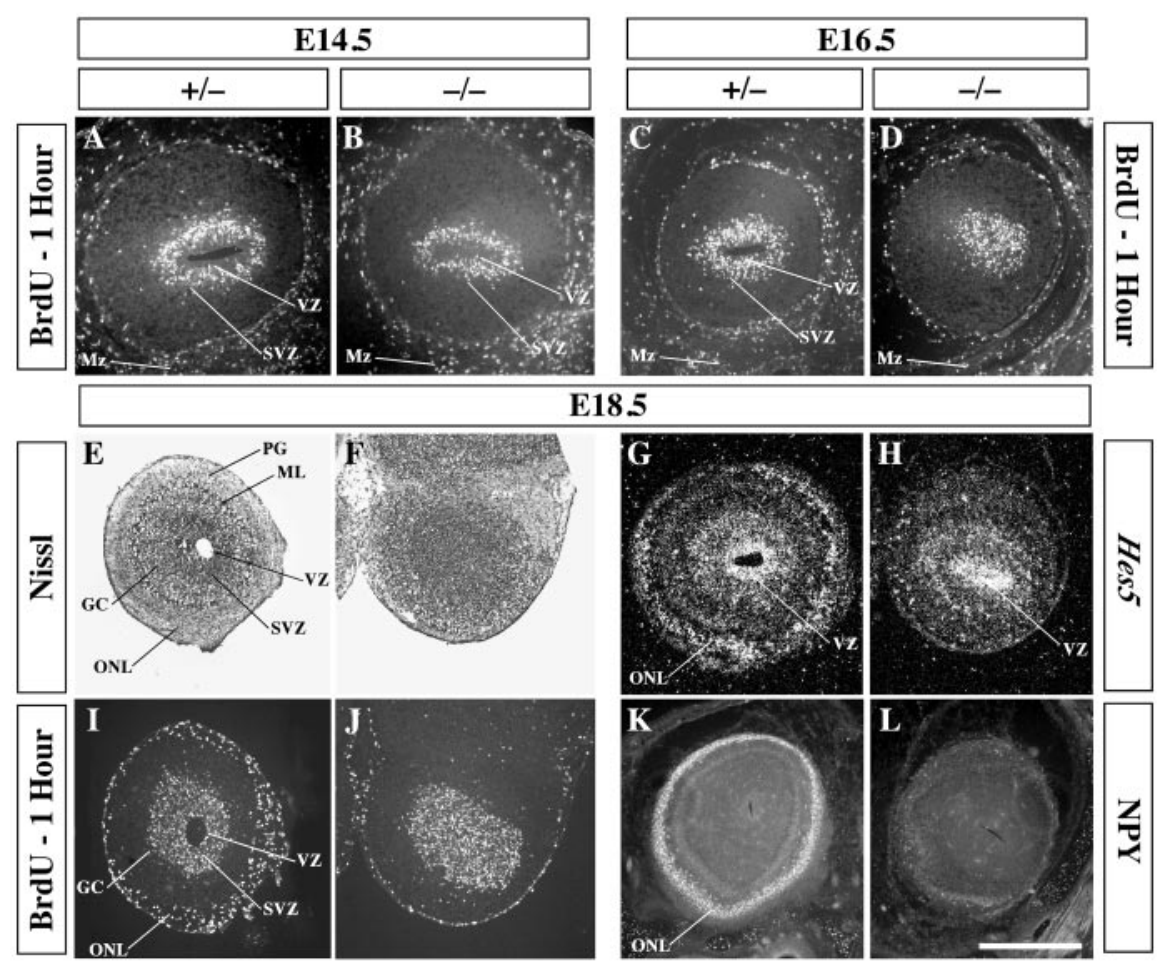

Figure 7. Proliferation assays reveal a loss of ONL cells. A $1 \mathrm{hr}$ pulse of BrdU given at E14.5 and E16.5 ( $A-D)$ labels mitotically active cells in the VZ, SVZ, ONL, and mesenchyme $(M Z)$ in and surrounding the OB. The density of BrdU-labeled cells appeared normal in the VZ, SVZ, and mesenchyme, whereas by E16.5, a decrease is apparent in the $D 1 \times 5^{-1-}$ mutants most superficial layer of the $\mathrm{OB}$ (arrowhead). A $1 \mathrm{hr}$ pulse of BrdU at E18.5 $(I, J)$ shows a large reduction in the number of BrdU-positive cells in the $D / \times 5^{-/-}$mutants most superficial layer of the $0 B$. Hes 5 expression, which marks many types of dividing cells, is also reduced in the $D / \times 5^{-/-}$mutants most superficial layer of the $O B(G, H)$. NPY expression in olfactory nerve ensheathing glia is lost in the $D / \times 5^{-1-}$ mutant $(K, L)$. Scale bar (in L): $A, B, 220 \mu \mathrm{m} ;(-F, I-L, 500 \mu \mathrm{m} ; G, H, 614 \mu \mathrm{m}$.

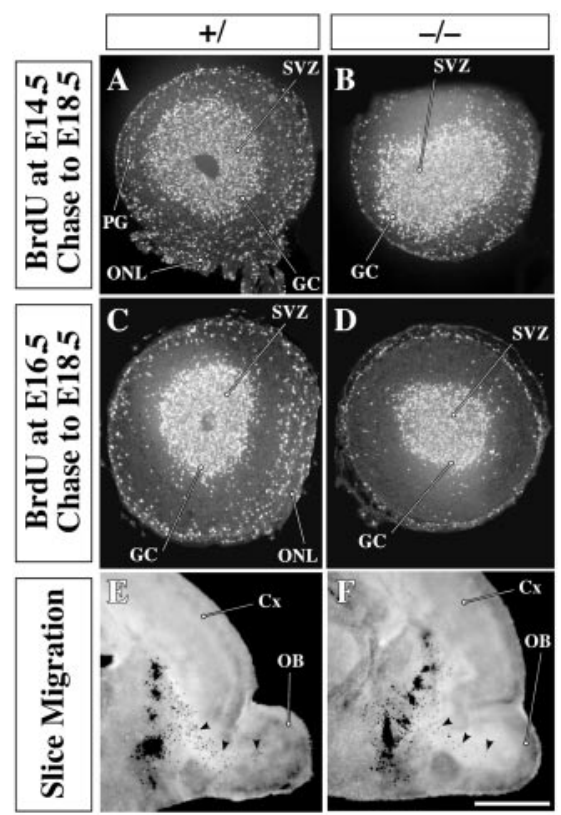

Figure 8. Migration assays in the $D / \times 5^{-/-}$mutant. A pulse of BrdU given at 114.5 with survival until E18.5 shows a reduction in the number of $B r d U^{+}$cells at the periphery of the $0 B$ in the $D / x 5^{-/-}$ mutant and an increase in the density of BrdU ${ }^{+}$cells within the SVZ $(A, B)$. A BrdU pulse at E16.5 with survival until E18.5 shows a clear reduction in the number of $\mathrm{BrdU}^{+}$cells in the mantle zone of the $\mathrm{OB}$ $(C, D)$. A LacZ-encoding replication incompetent retrovirus was injected into parasagittal slices from an E18.5 telencephalon into multiple positions along proximal positions of the RMS and then stained for $\beta$-galactosidase activity to identify the positions of LacZ-expressing migratory cells $(E, F$; shown by arrowheads). $(X$, Cortex. Scale bar (in $F$ ): $A-D, 445 \mu \mathrm{m} ; E, F, 1150 \mu \mathrm{m}$. of neuroepithelium. Thus, DLX5 is not essential for specification of the entire olfactory placode. Perhaps, other Dlx family members (e.g., Dlx6) compensate for early DLX5 function in this tissue; this possibility can be studied in $D l \times 5 \& 6^{-/-}$ mutants that have been generated recently (Robledo et al., 2002).

The OE is severely hypoplastic in the Dl $x 5^{-/-}$mutants (Figs. 1-3). As early as E10.5, Dl $x 5^{-/-}$mutants show reduced olfactory neuroepithelial structures (Fig. $1 C)$. At this point, it is uncertain whether the mutation causes a general hypoplasia or whether specific subdivisions of the $\mathrm{OE}$ are preferentially affected.

Loss of Dlx5 also affects the differentiation of the olfactory neurons. Although they can express NCAM, $\beta$-III tubulin and OMP (Fig. $2 B, D, F, H$ ), their axons fail to grow to the olfactory bulb. Although we cannot completely rule out the possibility that a few $\mathrm{OE}$ axons do contact the $\mathrm{OB}$, our analyses of Nissl-stained, Hoechst-stained, OMP, GAP43, S100, and calretinin immunohistochemistry, and DiI labeling of OE axons all support the observation that no axons contact the OB. The mechanism(s) underlying this defect could lie in either the olfactory neurons or the environment through which they navigate, because DLX5 function is required in the morphogenesis of frontonasal mesenchyme (Acampora et al., 1999; Depew et al., 1999) and in the differentiation of the $\mathrm{OB}$ (Figs. 3-9).

Associated with the $\mathrm{OE}$ and axonal abnormalities are the deficits in olfactory ensheathing glia in the $\mathrm{OB}$ nerve layer and gonadotrophin-releasing hormone (luteinizing hormonereleasing hormone) neurons in the forebrain of the $\mathrm{Dl}_{x 5^{-/-}} \mathrm{mu}-$ tants (Fig. $7 L, M$; and data not shown). These cell types are derived from the olfactory placode and migrate along the olfactory nerve (Doucette, 1993; Tobet et al., 1993). These deficiencies could be attributable to a role of DLX5 in the differentiation of these cell types and/or attributable to a defect in their migration that is secondary to the failure of olfactory nerve growth.

There is evidence that early olfactory axons may regulate cell cycle kinetics in the telencephalic anlage of the $\mathrm{OB}$ (Gong and Shipley, 1995). Although we have not directly ruled out this possibility, the fact that, in the absence of most olfactory axons, the $\mathrm{OB}$ is induced and its early neurogenesis (mitral cells) appears normal suggests that olfactory axons are not necessary for these processes. A similar result is observed in $\mathrm{Mash}^{-1-}$ mutants, which fail to produce olfactory neurons (Guillemot et al., 1993; Casarosa et al., 1999). However, Pax6 ${ }^{\text {sey/sey }}$ mutants also lack olfactory axons but have molecular features of a nonevaginated OB-like structure (Lopez-Mascaraque et al., 1998; Jimenez et al., 2000). The mechanism underlying the failure of $\mathrm{OB}$ evagination in $\mathrm{Pax}^{\text {sey/sey }}$ mutants may be secondary to PAX6 function in the olfactory epithelium and/or the telencephalon (Anchan et al., 1997).

Although olfactory axons are not essential for the induction and growth of the $\mathrm{OB}$, we provide evidence that they are required 


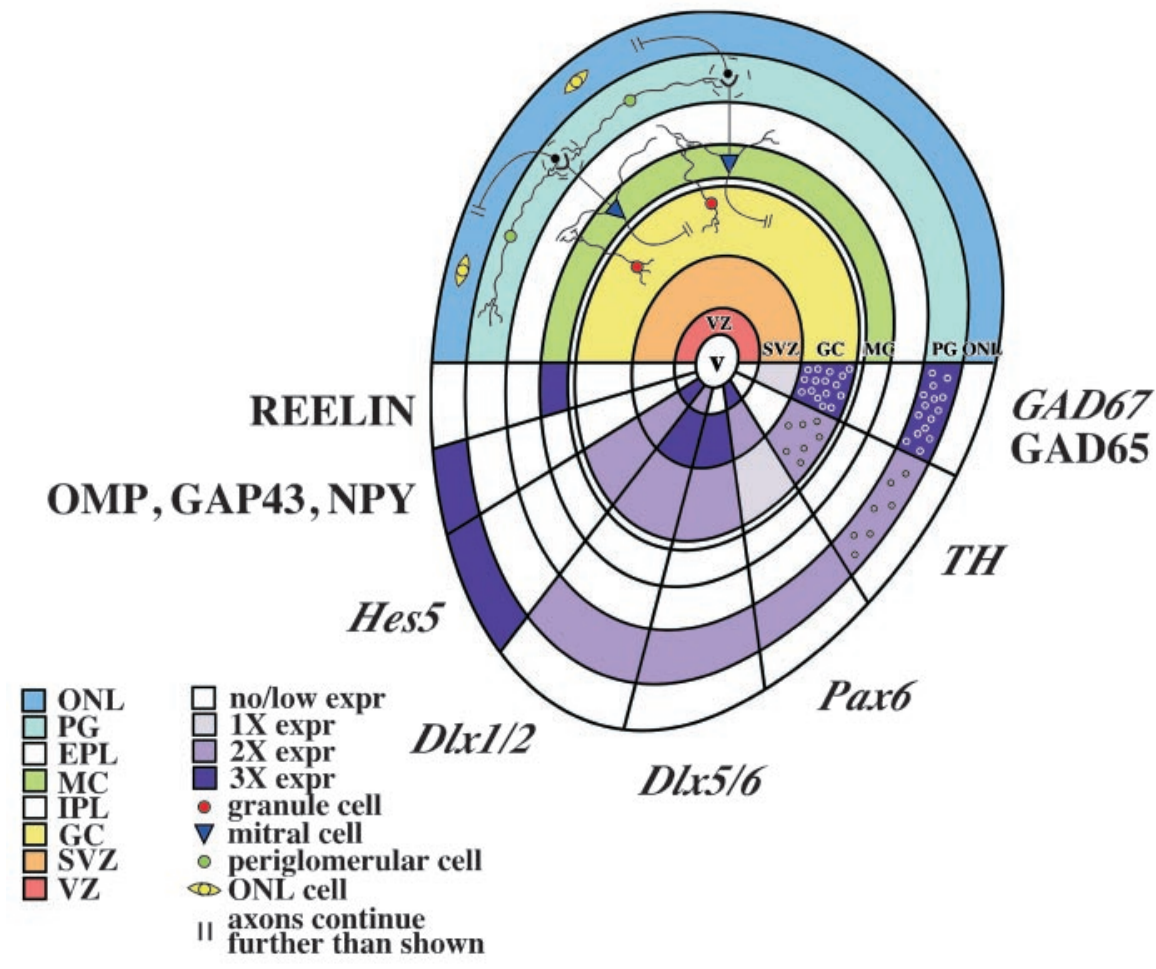

B

Dlx5 $5^{--}$Mutant

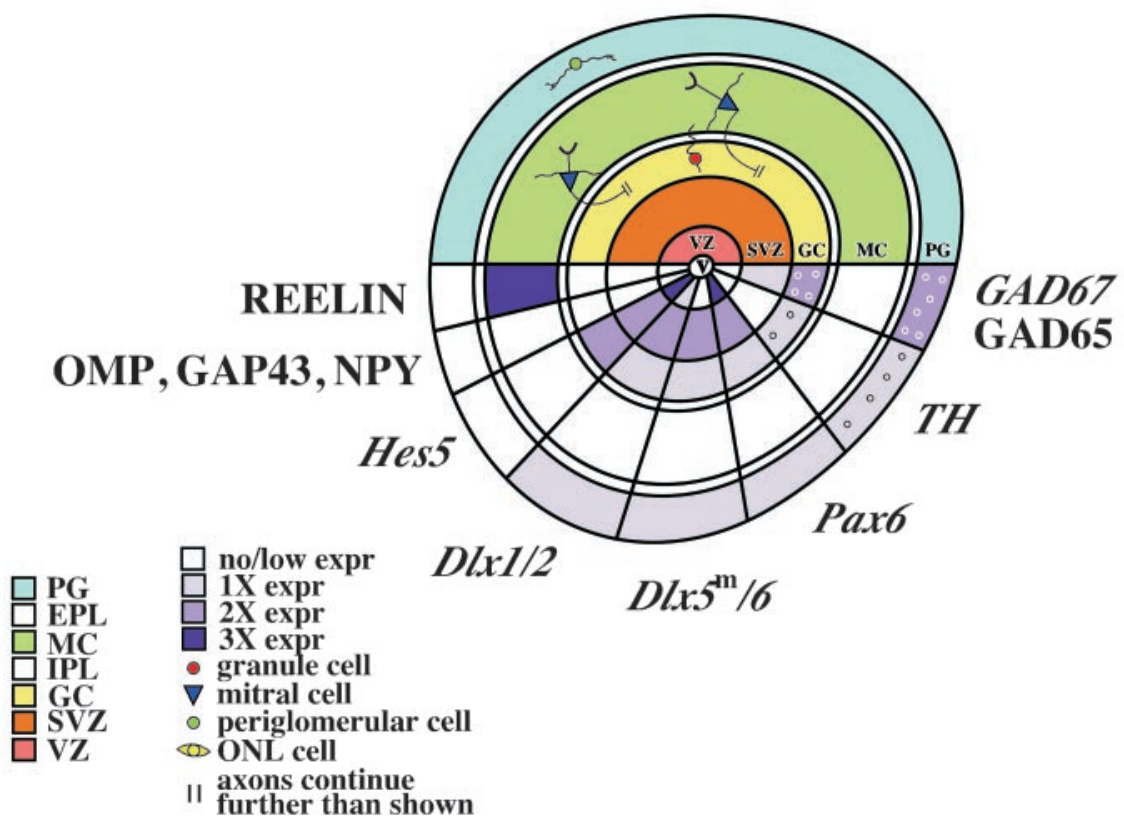

Figure 9. Diagrams showing $O B$ laminar organization and molecular expression in E18.5 wild-type $(A)$ and $D / x 5^{-/-}$mutants $(B)$. The top half of each $0 B$ shows the laminar organization (each color representing a different layer) and principal cell types. The bottom half of each $O B$ shows the expression of various genes, in which increasing color density represents increasing levels of expression. The top half of the mutant diagram illustrates that Dlx $5^{-/-}$mutants lack an ONL (blue), have a thicker MC (light green), and appear to have a defect in the migration of SVZ cells born at E14.5 (darker orange; see Fig. $8 A, B$ ). In addition, the mutation disrupts the radial orientation of the mitral cells (triangles) and their processes, reduces the numbers and alters the processes of periglomerular and granule cells (red and green circles), and virtually eliminates glia in the 0NL ( yellow spindles). The bottom half of the $D 1 \times 5^{-1-}$ mutant diagram illustrates the lack of an ONL, emphasized by the loss of OMP, GAP43, NPY, and Hes5 expression, shows the reduced expression of DIx1, DIx2, D/x $5^{m}$, DIX6, TH, GAD65, and GAD67 in the GC and PG, and the reduced expression of Pax6 in the PG. See figure for color and shape definitions. V, Olfactory ventricle. 
for its laminar properties. Nissl and Hoechst staining of Dlx $5^{-/-}$ mutant OBs fail to reveal normal laminar properties, despite the laminar expression of several GC, MC, and PG markers (Figs. 4, $6,7,9)$. The lack of histological lamination is not entirely attributable to the deficiencies in local circuit neurons, because Dlx1\& $2^{-/-}$mutants, which lack local circuit neurons, exhibit clear OB lamination (Bulfone et al., 1998). DiI labeling of mitral cells in the $D l \times 5^{-/-}$mutants shows that these cells lack a radial orientation and have hypoplastic dendritic trees. Reelin labeling shows that the mitral cell layer is thicker (Figs. 4O,P, 9), perhaps attributable to haphazard packing of mitral cell bodies (Fig. 6C$L)$. These non-autonomous effects, which may result from the lack of $\mathrm{OE}$ input, contribute to the defect in $\mathrm{OB}$ lamination in the Dl $\times 5^{-/-}$mutants. Thus, olfactory axons probably have a central role in organizing cellular morphogenesis of $\mathrm{OB}$ neurons.

\section{Dlx genes regulate the generation of olfactory bulb local circuit neurons}

$D l x 1, D l \times 2, D l \times 5$, and $D l x 6$ are expressed in the progenitors of $\mathrm{OB}$ local circuit neurons (Figs. 4, 5, 9) (Liu et al., 1997; Stuhmer et al., 2002a). Their expression is maintained in postmitotic granule and periglomerular neurons, albeit at a lower level (Fig. 4, 9) (Stuhmer et al., 2002a,b). Dl $x 2^{-/-}$mutants have greatly reduced numbers of $\mathrm{TH}^{+}$periglomerular cells $(\sim 80 \%)$ (Qiu et al., 1995), $D l \times 1^{-/-}$mutants less so $(\sim 15 \%$ reduction) (Long and Rubenstein, unpublished observations), whereas Dlx1 $2^{-1-}$ mutants lack most $\mathrm{GABA}^{+}$and $\mathrm{TH}^{+}$neurons (Bulfone et al., 1998) (Long

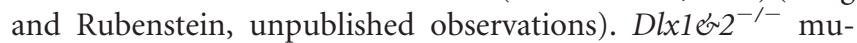
tants fail to express Dlx5 in the SVZ of most of the telencephalon; however, residual expression is found in part of the septum (Anderson et al., 1997; Zerucha et al., 1997). Through the analysis of the $D l \times 5^{-/-}$mutants, we demonstrated that the severe reduction of OB local circuit neurons in $D l \times 1 \& 2^{-/-}$mutants is not attributable only to the loss of Dlx5. In addition, we demonstrated that, like $D l \times 2^{-/-}$mutants, $D l \times 5^{-/-}$mutant mice have a hypomorphic OB local circuit neuron phenotype (Fig. 9). The Dl $x 5^{-/-}$mutation appears to preferentially affect granule cells as evidenced by the particularly severe reduction of GAD67, GAD65, and $T H$ expression in this layer (Fig. $4 E-H, K, L$ ). The reduction in $\mathrm{TH}$ expression could be caused by the lack of olfactory axons (Baker et al., 1983; Baker, 1990; Baker and Farbman, 1993). However, we suggest that a cell-autonomous mechanism contributes to this phenotype, because both $D l \times 2^{-1-}$ and Dlxl\&2 $2^{-/-}$mutants have fewer $\mathrm{TH}^{+}$PG cells, although the olfactory innervation appears to be normal (Qiu et al., 1995; Bulfone et al., 1998). At this point, it is unclear whether $D l \times 2^{-/-}$and Dl $x 5^{-1-}$ mutants have phenotypic differences in the production of local circuit neurons; ongoing work is aimed at elucidating the individual and combined roles of the $D l x$ genes in $\mathrm{OB}$ neurogenesis.

\section{$D l x$ and $G A D$ expression in the embryonic brain suggests pathways of olfactory bulb local circuit neuron migration} On the basis of the expression of $D l x 1, D l \times 2, D l \times 5$, and GAD67, there may be at least three distinct progenitor zones that contribute tangentially migrating precursors to OB local circuit neurons (Fig. 5A, C; and data not shown). Cells may migrate from the SVZ of the septum to medial parts of the OB (Fig. 5C), in addition to cells that may migrate from the SVZ of the MGE and LGE into lateral parts of the $\mathrm{OB}$ (Fig. $5 A$ ). In each case, these progenitors enter the ventral part of the OB (Fig. 5). We propose that the rostral convergence of the three embryonic pathways becomes the RMS. The number of progenitor zones and potential migra- tion pathways suggests that different subtypes of OB local circuit neurons may originate from distinct locations.

However, DLX5 function is not essential for the formation of these progenitor zones or potential migration pathways (Fig. $5 B, D, H, J)$. Indeed, in E18.5 Dl $x 5^{-1-}$ mutants, tangential migration along the RMS was detectable using the retroviral and DiIlabeling assays (Fig. 8E,F; and data not shown). We generally detected decreases in migration; however, because our assays were not quantitative, it is premature to conclude that DLX5 is essential for normal levels of migration in the RMS. Furthermore, we did not detect gross abnormalities in the proliferation of $\mathrm{OB}$ local circuit neuron progenitors in the Dlx $5^{-1-}$ mutants (Fig. 7; and data not shown). However, subtle defects in proliferation would not have been detected with our methods.

Thus, why do $D l x 5^{-1-}$ mutants have fewer GAD65 ${ }^{+}$, $\mathrm{GAD} 7^{+}$, and $\mathrm{TH}^{+}$neurons in the GC and PG (Figs. 4, 5, 9)? A BrdU pulse chase (E16.5-E18.5) shows a reduction in the number of cells that populate the $\mathrm{OB}$ mantle zone (Fig. $8 C, D$ ). This suggests that the reduction in $\mathrm{OB}$ local circuit neurons is attributable to their reduced production. If the defect were attributable to reduced migration of postmitotic neurons, we would have observed periventricular ectopic collections of postmitotic neurons. Unlike the $D l x 1 \& 2^{-/-}$mutants, in which this is a prominent aspect of their phenotype in the basal ganglia (Anderson et al., 1997; Marin et al., 2000), periventricular ectopic neurons were not found in the $D l \times 5^{-/-}$mutants. Therefore, we suggest that DLX5 is necessary for progenitors in the SVZ of the OB to mature into postmitotic local circuit neurons. This defect could cause an expansion of the progenitor zone (Fig. 9). This would be consistent with the apparent accumulation of BrdU-labeled cells in the SVZ in the BrdU pulse chase (E14.5-E18.5) (Fig. 8A,B). Furthermore, although there is not a massive expansion of the SVZ, this defect could explain why the olfactory ventricle is smaller in most mutants (Fig. 2, 4, 6-8). Thus, future studies will focus on establishing how DLX5 regulates the transition from SVZ-type progenitor to neuron.

\section{References}

Acampora D, Merlo GR, Paleari L, Zerega B, Postiglione MP, Mantero S, Bober E, Barbieri O, Simeone A, Levi G (1999) Craniofacial, vestibular and bone defects in mice lacking the Distal-less-related gene Dlx5. Development 126:3795-3809.

Akazawa C, Sasai Y, Nakanishi S, Kageyama R (1992) Molecular characterization of a rat negative regulator with a basic helix-loop-helix structure predominantly expressed in the developing nervous system. J Biol Chem 267:21879-21885.

Altman J (1969) Autoradiographic and histological studies of postnatal neurogenesis. IV. Cell proliferation and migration in the anterior forebrain, with special reference to persisting neurogenesis in the olfactory bulb. J Comp Neurol 137:433-457.

Anchan RM, Drake DP, Haines CF, Gerwe EA, LaMantia AS (1997) Disruption of local retinoid-mediated gene expression accompanies abnormal development in the mammalian olfactory pathway. J Comp Neurol 379:171-184.

Anderson SA, Qiu M, Bulfone A, Eisenstat DD, Meneses J, Pedersen R, Rubenstein JL (1997) Mutations of the homeobox genes Dlx-1 and Dlx-2 disrupt the striatal subventricular zone and differentiation of late born striatal neurons. Neuron 19:27-37.

Baker H (1990) Unilateral, neonatal olfactory deprivation alters tyrosine hydroxylase expression but not aromatic amino acid decarboxylase or GABA immunoreactivity. Neuroscience 36:761-771.

Baker H, Farbman AI (1993) Olfactory afferent regulation of the dopamine phenotype in the fetal rat olfactory system. Neuroscience 52:115-134.

Baker H, Kawano T, Margolis FL, Joh TH (1983) Transneuronal regulation of tyrosine hydroxylase expression in olfactory bulb of mouse and rat. J Neurosci 3:69-78.

Baker H, Liu N, Chun HS, Saino S, Berlin R, Volpe B, Son JH (2001) Phe- 
notypic differentiation during migration of dopaminergic progenitor cells to the olfactory bulb. J Neurosci 21:8505-8513.

Behar T, Ma W, Hudson L, Barker JL (1994) Analysis of the anatomical distribution of GAD67 mRNA encoding truncated glutamic acid decarboxylase proteins in the embryonic rat brain. Brain Res Dev Brain Res 77:77-87.

Bulfone A, Puelles L, Porteus MH, Frohman MA, Martin GR, Rubenstein JL (1993) Spatially restricted expression of Dlx-1, Dlx-2 (Tes-1), Gbx-2, and Wnt-3 in the embryonic day 12.5 mouse forebrain defines potential transverse and longitudinal segmental boundaries. J Neurosci 13:3155-3172.

Bulfone A, Wang F, Hevner R, Anderson S, Cutforth T, Chen S, Meneses J, Pedersen R, Axel R, Rubenstein JL (1998) An olfactory sensory map develops in the absence of normal projection neurons or GABAergic interneurons. Neuron 21:1273-1282.

Casarosa S, Fode C, Guillemot F (1999) Mash1 regulates neurogenesis in the ventral telencephalon. Development 126:525-534.

De Carlos JA, Lopez-Mascaraque L, Valverde F (1995) The telencephalic vesicles are innervated by olfactory placode-derived cells: a possible mechanism to induce neocortical development. Neuroscience 68:1167-1178.

Dellovade TL, Pfaff DW, Schwanzel-Fukuda M (1998) Olfactory bulb development is altered in small-eye (Sey) mice. J Comp Neurol 402:402-418.

Depew MJ, Liu JK, Long JE, Presley R, Meneses JJ, Pedersen RA, Rubenstein JL (1999) Dlx5 regulates regional development of the branchial arches and sensory capsules. Development 126:3831-3846.

Dolle P, Price M, Duboule D (1992) Expression of the murine Dlx-1 homeobox gene during facial, ocular and limb development. Differentiation 49:93-99.

Doucette R (1993) Glial cells in the nerve fiber layer of the main olfactory bulb of embryonic and adult mammals. Microsc Res Tech 24:113-130.

Eisenstat DD, Liu JK, Mione M, Zhong W, Yu G, Anderson SA, Ghattas I, Puelles L, Rubenstein JL (1999) DLX-1, DLX-2, and DLX-5 expression define distinct stages of basal forebrain differentiation. J Comp Neurol 414:217-237.

Esclapez M, Tillakaratne NJ, Kaufman DL, Tobin AJ, Houser CR (1994) Comparative localization of two forms of glutamic acid decarboxylase and their mRNAs in rat brain supports the concept of functional differences between the forms. J Neurosci 14:1834-1855.

Feldblum S, Erlander MG, Tobin AJ (1993) Different distributions of GAD65 and GAD67 mRNAs suggest that the two glutamate decarboxylases play distinctive functional roles. J Neurosci Res 34:689-706.

Gall CM, Hendry SH, Seroogy KB, Jones EG, Haycock JW (1987) Evidence for coexistence of GABA and dopamine in neurons of the rat olfactory bulb. J Comp Neurol 266:307-318.

Goldman SA, Luskin MB (1998) Strategies utilized by migrating neurons of the postnatal vertebrate forebrain. Trends Neurosci 21:107-114.

Gong Q, Shipley MT (1995) Evidence that pioneer olfactory axons regulate telencephalon cell cycle kinetics to induce the formation of the olfactory bulb. Neuron 14:91-101.

Graziadei PP, Monti-Graziadei AG (1992) The influence of the olfactory placode on the development of the telencephalon in Xenopus laevis. Neuroscience 46:617-629.

Guillemot F, Lo LC, Johnson JE, Auerbach A, Anderson DJ, Joyner AL (1993) Mammalian achaete-scute homolog 1 is required for the early development of olfactory and autonomic neurons. Cell 75:463-476.

Hinds JW (1968a) Autoradiographic study of histogenesis in the mouse olfactory bulb. I. Time of origin of neurons and neuroglia. J Comp Neurol 134:287-304.

Hinds JW (1968b) Autoradiographic study of histogenesis in the mouse olfactory bulb. II. Cell proliferation and migration. J Comp Neurol 134:305-322.

Hinds JW (1972a) Early neuron differentiation in the mouse of olfactory bulb. I. Light microscopy. J Comp Neurol 146:233-252.

Hinds JW (1972b) Early neuron differentiation in the mouse olfactory bulb. II. Electron microscopy. J Comp Neurol 146:253-276.

Jimenez D, Garcia C, de Castro F, Chedotal A, Sotelo C, de Carlos JA,
Valverde F, Lopez-Mascaraque L (2000) Evidence for intrinsic development of olfactory structures in Pax-6 mutant mice. J Comp Neurol 428:511-526.

Kosaka K, Aika Y, Toida K, Heizmann CW, Hunziker W, Jacobowitz DM, Nagatsu I, Streit P, Visser TJ, Kosaka T (1995) Chemically defined neuron groups and their subpopulations in the glomerular layer of the rat main olfactory bulb. Neurosci Res 23:73-88.

LaMantia AS, Colbert MC, Linney E (1993) Retinoic acid induction and regional differentiation prefigure olfactory pathway formation in the mammalian forebrain. Neuron 10:1035-1048.

LaMantia AS, Bhasin N, Rhodes K, Heemskerk J (2000) Mesenchymal/epithelial induction mediates olfactory pathway formation. Neuron 28:411-425.

Liu JK, Ghattas I, Liu S, Chen S, Rubenstein JL (1997) Dlx genes encode DNA-binding proteins that are expressed in an overlapping and sequential pattern during basal ganglia differentiation. Dev Dyn 210:498-512.

Lois C, Alvarez-Buylla A (1994) Long-distance neuronal migration in the adult mammalian brain. Science 264:1145-1148.

Lopez-Mascaraque L, Garcia C, Valverde F, de Carlos JA (1998) Central olfactory structures in Pax-6 mutant mice. Ann NY Acad Sci 855:83-94.

Luskin MB (1993) Restricted proliferation and migration of postnatally generated neurons derived from the forebrain subventricular zone. Neuron 11:173-189.

Mallamaci A, Di Blas E, Briata P, Boncinelli E, Corte G (1996) OTX2 homeoprotein in the developing central nervous system and migratory cells of the olfactory area. Mech Dev 58:165-178.

Marin O, Rubenstein JL (2001) A long, remarkable journey: tangential migration in the telencephalon. Nat Rev Neurosci 2:780-790.

Marin O, Anderson SA, Rubenstein JL (2000) Origin and molecular specification of striatal interneurons. J Neurosci 20:6063-6076.

Neuman T, Keen A, Zuber MX, Kristjansson GI, Gruss P, Nornes HO (1993) Neuronal expression of regulatory helix-loop-helix factor Id2 gene in mouse. Dev Biol 160:186-195.

Qiu M, Bulfone A, Martinez S, Meneses JJ, Shimamura K, Pedersen RA, Rubenstein JL (1995) Null mutation of Dlx-2 results in abnormal morphogenesis of proximal first and second branchial arch derivatives and abnormal differentiation in the forebrain. Genes Dev 9:2523-2538.

Robledo RF, Rajan L, Li X, Lufkin T (2002) The Dlx5 and Dlx6 homeobox genes are essential for craniofacial, axial, and appendicular skeletal development. Genes Dev 16:1089-1101.

Shepherd GM (1998) The synaptic organization of the brain, Ed 4. New York: Oxford UP.

Stoykova A, Gruss P (1994) Roles of Pax-genes in developing and adult brain as suggested by expression patterns. J Neurosci 14:1395-1412.

Stuhmer T, Anderson SA, Ekker M, Rubenstein JL (2002a) Ectopic expression of the Dlx genes induces glutamic acid decarboxylase and Dlx expression. Development 129:245-252.

Stuhmer T, Puelles L, Ekker M, Rubenstein JL (2002b) Expression from a Dlx gene enhancer marks adult mouse cortical GABAergic neurons. Cereb Cortex 12:75-85.

Tobet SA, Crandall JE, Schwarting GA (1993) Relationship of migrating luteinizing hormone-releasing hormone neurons to unique olfactory system glycoconjugates in embryonic rats. Dev Biol 155:471-482.

Tobet SA, Hanna IK, Schwarting GA (1996) Migration of neurons containing gonadotropin releasing hormone $(\mathrm{GnRH})$ in slices from embryonic nasal compartment and forebrain. Brain Res Dev Brain Res 97:287-292.

Toida K, Kosaka K, Aika Y, Kosaka T (2000) Chemically defined neuron groups and their subpopulations in the glomerular layer of the rat main olfactory bulb-IV. Intraglomerular synapses of tyrosine hydroxylaseimmunoreactive neurons. Neuroscience 101:11-17.

Ubink R, Hokfelt T (2000) Neuropeptide Y expression in Schwann cell precursors. Glia 32:71-83.

Ubink R, Halasz N, Zhang X, Dagerlind A, Hokfelt T (1994) Neuropeptide tyrosine is expressed in ensheathing cells around the olfactory nerves in the rat olfactory bulb. Neuroscience 60:709-726.

Zerucha T, Muller JP, Chartrand N, Ekker M (1997) Cross-interactions between two members of the Dlx family of homeobox-containing genes during zebrafish development. Biochem Cell Biol 75:613-622. 